\title{
A Amizade como o Fim do Direito em Aristóteles
}

\author{
Alejandro Montiel Alvarez
}

1 Introduçâ. 2 A Justiça 3 A Amízade 4 A Amizade como o Fím do Direito. 5 Conclusão. Referências.

Resumo: Este artigo busca estudar a inter-relacăo entre as duas formas basicas dos homens se relacionarem - a amizade e a fustiç - e sua implicaçao no Direito, atraves da teoria anistotelica, principalmente, delimitar o objeto do Direito na justica e sua finalidade na amizade.

Palavras-chave: Direito Filosofia Filosofia do Direito. Etica. Aristóteles. Ética a Nicómaco. Ética a Eudémo. Teoria da Justiça. Amizade.

Abstract: This paper intends to study the interrelation between the two basic forms of men interacting to each other - Friendship and Justice - and it 's implication on Law based on the Anistotelian theory; especially to bound the object of Law in Justice and the aim of Law in Friendship.

Keywords: Law. Philosophy. Philosophy of Law Ethics. Aristotle. Nicomachean Ethics. Eudemian Ethics. Justice Theory. Friendship.

\section{Introdução}

Para entender o direito, como compreendido na Tradição Aristotélica, deve-se entender a inter-relação entre as duas formas básicas dos homens se relacionarem: a amizade e a justiça. Estas têm entre si muitas semelhanças, como se desenvolverá melhor no decorrer de suas análises no corpo deste trabalho. Entre essas semelhanças, pode-se observar que ambas se situam dentro do mesmo âmbito, dividem o mesmo objeto e o mesmo sujeito e, ainda, têm a mesma extensāo. Isto é, em toda a comunidade (âmbito) existe algum tipo de justuça e também de amizade; a amizade e a justiça se referem às mesmas coisas (objeto); pertencem às mesmas pessoas (sujeito); e têm a mesma extensão. Além dessas semelhanças,

\footnotetext{
Mestre em Filosofia do Direito pela Universidade Federal do Rio Grande do Sul (UFRGS) e Doutorando em Filosofia do Direito pela mesma Universidade.
} 
as duas têm em comum o grande interesse de Aristóteles em sua investigação. Enquanto à amizade são dedicados dois livros dos dez da EN e mais um entre os oito da EE; à Justiça nâo só é dedicado um Livro em cada uma das Éticas, como também uma de suas obras perdidas, Da Justiça, citada por Cícero. Em que pese o grande interesse de Aristóteles por estas teorias na Etica, é na Política que o Filósofo demonstra seu príncipal uso.

Tanto a amizade quanto a justiça dizem respeito a uma relaçâo: ${ }^{2}$ a relação de igualdade ou desigualdade que é própria da política e é matéria do direito. Aqueles que são iguais em cidadania, e têm acesso à esfera pública, e aqueles que são desiguais, e buscam essa igualdade, se relacionam apenas de duas formas: ou por amizade; ou por justica. De tal forma que ambas, nas suas diferentes formas, săo constitutivas do fenômeno político. E dão conteúdo à ação política e ao direito, uma vez que esses são fenômenos sempre relacionaís.

\section{A Justiça}

O termo homérico para designar, em geral, o direito era themis, o qual indicava o compêndio das grandezas cavaleirescas que, etimologicamente, significava 'lei". O conceito de dike, por outro lado, não é claro, vem da linguagem processual, de dar e receber dike - o culpado 'dava dike' ao lesado que a recebia. É daí que vem o sentido dado ao termo na polis, posterior aos tempos homéricos: "[...] equivale aproximadamente a dar a cada um o que lhe é devido" " Então, dike passou a significar o cumprimento da justiça, ao contrário de themis, que se referia à autoridade, à legalidade e à validade do direito, dando, assim, vazão para que, a partir das lutas sociais na Grécia, a bandeira das massas passasse a ser a busca pelo direito (dike) e o fim da lei autoritária (themis).

AQUINO, Tomás de Comentános a la Ética a Nicomaco de Aristóteles, VII Liçấo $\mathbb{I X}$; 1180 .

3 JAEGER, Werner, Faidéla. São Paulo: Martins Fontes, 2001 , p. 135. 
Foi o sentido de igualdade presente na acepção de dike ('devolver exatamente o que se recebeu') que norteou a busca por uma medida justa para a atribuição do direito. $\mathrm{O}$ procesṣo de expansão e mecanização da igualdade se dá em duas etapas: (a) as massas lutaram contra a themis que expressava a lei autoritária da nobreza, conquistando o governo; (b) posteriormente, em razáo dos excessos causados pelo governo das massas, buscou-se (movimento realizado também pelos nobres) que a dike fosse expressa em lei escrita, para dar efetividade à igualdade. Essa evolução também se deu no campo da linguagem. Faltava um conceito próprio daquela proteção contra as transgressóes, assim, adotou-se o termo abstrato dikaiosyne, que passou a ser a virtude do homem grego dos tempos pós-homéricos. ${ }^{4}$

Inserido nesse contexto, Aristóteles, no Tratado da Justiça, demonstra exatamente o seu lugar e papel na evolução moral grega. $\mathrm{O}$ Livro $\mathrm{V}$ é baseado nos dois sentidos correntes da palavra justo (dikaion) - legal e igual. Aristóteles, o primeiro a sistematizar a justiça, propõe sua divisão - em legal e igual $^{5}$ - conforme o seu duplo aspecto: themis e dike: a primeira expressa-se no justo geral, correspondente à visẫo aristocrática das virtudes; enquanto a última expressa-se na justiça particular, cujo fundamento está na virtude própria da democracia - a dikaiosyne. Contudo, esse tratado é uma evidência da decadência da pólis. A justiça fundada na igualdade e na liberdade de todos os cidadãos deixava de existir no momento em que Aristóteles escrevia a Etica a Nicômaco, não havendo mais lugar, portanto, para a realização das virrudes. Ele, então, pretendia refundar a justiça nas relaçóes concretas existentes em toda sociedade, sem jamais esquecer que a justiça nâo se reduz apenas a fazer coisas justas, mas que necessita de uma disposiçăo interior. ${ }^{6}$

\footnotetext{
4 JAEGER, Werner. Paidéia. São Paulo: Martins Fontes, 2001. P. 134 - 138.

s Os quais foram claramente distinguidos apenas em Aristóteles. Ver: Gauthier e Jolif. L'Ethique a Nicomaque, Éditions Béatrice-Natwelaerts. Paris: 1959, F. 327.

"Gauthier e Jolif. L'Ethique a Nicomaque, Editions Béatrice-Nauwelaers, Paris: 1959. p. $327-328$
} 
É sobre essa teoria da justiça que Aristóteles desenvolve sua teoria jurídica - a qual terá influência preponderante nos séculos seguintes ${ }^{7}$ - sendo, portanto, a identidade do direito em Aristóteles fundada na justiça; sua causa formal.

Segundo Aristóteles: “[a] justiça é uma virtude pela qual cada um tem o seu segundo a lei; enquanto que a injustiça é um vício, pelo qual se possui o alheio contrariamente ao que ordena a lei" . Para formular o conceito de justiça (dikaiosyne), Aristóteles parte, novamente, de uma opinião compartilhada, qual seja, a justiça é um hábito (héxis) pelo qual alguém está disposto a: a) praticar o justo (dikaion), b) agir justamente e c) querer o que é justo. $\mathrm{Na}$ seqüência, com base nisso, ${ }^{9}$ propõe seu método, aplica a potência dos contrários; ${ }^{10}$ assim, de uma análise negativa, ou seja, através da análise do injusto, infere que, da mesma forma que se dá o injusto, se dará o justo. $\mathrm{O}$ injusto diz respeito ao ilegal e ao desigual, assim, o justo diz respeito ao legal (nomimon) e ao igual (ison). ${ }^{\text {it }}$

Para entender melhor o desenvolvimento disso, se faz necessário adiantar que Aristóteles expõe a justiça sob duplo aspecto:

a) como forma de se relacionar com os demais membros da comunidade (virtude completa); ou seja, a justiça , como virtude completa, é a expressão de qualquer das virtudes de determinado agente (coragem, temperança, prudência...) usada para a realização do bem de toda comunidade. ${ }^{1 \tilde{}} \mathrm{O}$

\footnotetext{
7 FREUND, Julien. Politique et Impolitique Paris Editions Sirey, 1987. P. 283 - 284. Ver também: Wener Jaeger. Paidéja. São Paulo: Martins Fontes, 2001. P. 139.

${ }^{8}$ Ret., Livro I, $1366 \mathrm{~b}$.

${ }^{9}$ Aristóteles utiliza, assim, o método típico da dialética. Gauthier e Jolif. lethique a Nicomaque - Introduction, tradution et commentaire. F 330.

10 A potência dos contrários é primordialmente, o método de circurscrição do objeto. Assim como a matemática trata dos pares e dos ímpares e a medicina da saúde e da doença. Para uma análise dos contrấnos, ver Tópicos, $\mathrm{II}_{*} 7,112$ b 27 e ss:

"Antes de Aristóteles, as noçöes de legal e igual, assin como, de ilegal e de desigual eram intercambiávers. E na EN que esta distinção se tornou clara. Gauthier et Jolif. Léthique a Nicomaque - Introduction, tradution et commentaire: P. 336.

12. "O termo 'geral' aplicado a este tipo de justiça refere-se à sua abrangencia: todos os atos, independentemente da sua natureza, na medida em que săo devidos à comunidade
} 
exemplo dado por Aristóteles é a ação de um guerreiro ao enfrentar a batalha, cujo aspecto é duplo: em relaçẩo ao agente (o guerreiro), é um ato de coragem (expressão da justiça particular), ao passo que, em relaçăo à comunidade, é um ato de justiça (expressão da virtude completa), ou seja, é aquilo devido à comunidade;

b) como hábito (uirtude particular), cuja natureza năo é distinta das demais virtudes particulares (como coragem, prudência, temperança etc). ${ }^{3}$

Conclui-se, assim, que a justiça é sempre relacional, isto é, sempre tem por finalidade o bem do outro. ${ }^{14}$ Porém, enquanto a justiça geral (virtude completa) visa diretamente ao bem da comunidade em geral - o bem comum - e indiretamente ao bem dos indivíduos, a justiça particular (virtude particular) visa diretamente ao bem do particular e indiretamente, ao bem comum. ${ }^{15}$

Voltando ao desenvolvimento da idéia de justo como legal e como igual tem-se que a idéia do justo geral se alicerça na expressão legal do justo, ${ }^{16}$ pois as leis: a) se ocupam de todas as matérias (principalmente, as demais virtudes); b) buscam ao bem comum (de acordo com o definido por cada diferente regime), e, c) determinam o próprio de cada um. Chega-se, portanto, ao justo que produz ou preserva a felicidade ou seus elementos para a comunidade política. ${ }^{17} \mathrm{E}$ a ação justa, do ponto de vista geral, é a adequação da ação ao que é devido à comunidade. De tal forma, alêm da justiça

para que esta realize o seu bem, constituem deveres de justiça . Luis Femando Barzotto. Justiça Social Revista do Ministério Púbilico do Rio Grande do Sul, v. 50, 2003. P. 21 .

I. EN, V, 1129 b. 20-1130 a, 10 .

14 Somente a justiça parece referir-se a um bem alheio, que em relaçăo ao outro, enquanto tende a agir o que é útil para o outro, para a comunidade ou para seus govemantes AQUINO, Tomás de Comentario a la Ética a Nicomaco de Aristoteles; V. 643 .

is AQUINO, Tomás de Comentario a la Élica a Nicómaco de Aristóteles, V, Liçấ III, 650. Ver também: Ret, Livro $1,1373 \mathrm{~b}$.

6 BARZOTTO Luis Fernando Justiça Social Revista do Ministério Público do Rio Grande do Sul, v. 50, 2003. P. 20 - 21.

EN, V, 1129 b $1-15$. 
geral, existe, também, uma justiça particular, a qual subjaz a idéia do justo como igual. Esta (a justiça particular) é apenas uma virtude entre as demais (relação de gênero e espécie); faz parte da justiça geral. Em seu contrário, há uma injustiça particular 18

Toda ação que viola a lel, portanto, faz parte da injustiça geral e, também, corresponde a um vício particular, como: cometer adultério é, em relaçâo à justiça geral, um ato injusto para com a comunidade, mas como vício, é uma ação licenciosa. Ocorre que certos vícios são cometidos impropriamente aos fins de determinadas açōes, como cometer adultério em vista de ganhos materiais. Neste caso, o vício cometido não pode mais ser uma açăo licenciosa. A injustiça particular vem preencher a lacuna existente entre os vícios apresentados. Há uma injustiça particular sempre que o agente vise ter mais bens e menos males do que lhe corresponde; conseqüentemente, há uma justiça particular sempre que se vise alcançar o devido nas parcelas de bens e males. Ou seja, a injustiça particular é um vício impróprio, o qual pode se manifestar nos mais diversos tipos de ação. ${ }^{20}$

A matéria própria do direito, nos estudos aristotélicos, reside no ato de atribuir o próprio de cada um ou seja, no ato de dar a cada um o "devido", para que seja (re)estabelecida a igualdade. $O$ "devido" dá-se de diferentes formas: ao passo que, o devido na justiça geral é a conformidade das açổes dos indivíduos às disposiçóes da comunidade na forma da lei; na justiça particular, o devido é a igualdade. A igualdade, por sua vez, se estabelece exatamente no termo médio entre alguma das partes "ter em excesso" ou "ter em falta", pois o devido é a igualdade, e a igualdade, para Aristóteles, é o melo termo. A igualdade, porém, pode se formar entre diferentes

\footnotetext{
18 Tomás de Aquino comenta que Aristóteles procede assim, pois os hábitos se manifestam por seus contrarios. Comentario a la Ética a Nicómaco Ge Aristóteles, V, Liçä̀ III, 647.

19. Pois a todo tipo de injustiça geral corresponde um vício específico, ou seja, violar a lei em busca de um ganho pessoal corresponde ao vicio da injustiça particular. $\mathrm{EN}, \mathrm{V} .1130$ a 27.

${ }^{20} \mathrm{EN}_{*} \mathrm{~V}_{0} 1130$ a $15-35$.
} 
termos comparativos (pessoas, coisas, açōes e as diversas formas de combinaçōes destes termos). ${ }^{21}$ Em razão disso, a justiça particular subdivide-se em justiça distributiva e justiça corretiva: a justiça distributtiva é aquela que se aplica à distribuição dos bens ou dos males entre os membros da comunidade, por exemplo, honras e trabalhos pesados, igualando pessoas a coisas; enquanto a justiça corretiva diz respeito aos tratos nas relaçōes entre os indivíduos (voluntários ou involuntários), igualando coisa com coisa. ${ }^{22}$

A justiça distributiva opera na distribuição tanto dos bens quanto dos males ${ }^{23}$ da comunidade aos seus membros - relação da comunidade com seus membros -, ou seja, na atribuição de coisas que, em um primeiro momento, são comuns a determinados indivíduos; baseia-se em um critério ${ }^{24}$ ao qual subjaz a igualdade dos membros que concorrem aos bens $^{25}$ escassos da comunidade. Assim, se estabelece ao menos quatro termos - duas pessoas $(\mathrm{A} \mathrm{e} \mathrm{B})$ e dois bens ${ }^{26}(\mathrm{C} \mathrm{e}$ D) - nos quais percebe-se duas relações distintas: A está para C; e B está para D. A justiça distributiva é a proporção dessas duas relações, a qual Aristóteles define como proporção geométrica: A está para C assim como B está para D. ${ }^{27}$ Por exemplo, o soldado $X$ destacou-se em uma batalha e ganhou uma medalha, o soldado $\mathrm{Y}$ destacou-se em duas batalhas $\mathrm{e}$ ganhou duas medalhas. Ou seja, os soldados X e $Y$ são as

\footnotetext{
2) EN, V, $1131 \mathrm{a}, 10-20$

${ }^{22} \mathrm{EN}, \mathrm{V}, 1130$ b. $30-1131$ a. 5 .

23. "Pois o que age injustamente em relaçäo aos bens toma mais para si; mas a que padece uma injustiça recebe de menos. Nos males, ocorre o contráno; porque o mal menor tem razăo de bem por comparação ao mal maior jấ que aquilo que é menos mal é mais elegivel do que aquilo que é mais mal". AQUiNo, Tomás de. Comentario a la Ética a Nicómaco de Aristóteles, $V_{i} 670$.

2s O qual Aristóteles chama de mérito.

${ }^{25}$ Ou males, que podem ser reduzidos a bens quando considerados como males evítados.

26 Pode ser apenas um bem que, no entanto, será mencionado duas vezes na proporção (continua, segundo Aristóteles), por exemplo, A está para $B$, assim como $C$ está para $B$. De tal forma que os quatro termos restam mantidos. EN,, 1131 a, 30 . Também pode se considerar a ausência de um bern devido, por exemplo, A está para $B$, assim como $C$ está para $-B$.

${ }_{27} \mathrm{EN}, \mathrm{V}, 1131$ a, $10-1131 \mathrm{~b}, 24$.
} 
pessoas, as medalhas são os bens e a bravura em batalha o critério de distribuição pertencente às pessoas $\mathrm{X}$ e Y. Logo, duas medalhas de $Y$ estão para seu destaque em duas batalhas assim como uma medalha de $\mathrm{X}$ está para seu destaque em uma batalha, isto é, dois está para dois, assim como, um está para um $(2 / 2=1 / 1)$ - uma igualdade de proporções.

A injustiça (e as disputas políticas nas sociedades) dá-se quando partes iguais não recebem o mesmo, ou quando partes diferentes recebem o mesmo, de tal forma que o mais importante na justiça distributiva não é o objeto da distribuição ou a distribuição em si, porém, o critério de distribuição; o que é estabelecido dentro da esfera política, porém, com matéria dada pela ética. Por exemplo, uma disputa típica do século XX: mulheres terem direito ao voto. Isto nada mais era do que uma disputa por um critério de distribuição, isto é, homens e mulheres sendo iguais como membros da comunidade, logo, deveriam receber o mesmo: o direito ao voto - na proporção homens e voto e mulheres e voto deve haver a mesma relação. Segundo Tomás de Aquino:

No entanto, a dignidade concernente à distribuição não é obtida de acordo com um mesmo padrão a todos os homens: senão que em um sistema democrático, aonde todos governam, se alcança a dignidade segundo a liberdade. Como os homens comuns são iguais aos demais em liberdade, por isso, se considera que são dignos de serem governados da mesma maneira. Por outrolado, em uma oligarquia, aonde uns poucos governam, se mede a dignidade segundo as riquezas ou a linhagem, de tal forma que os que têm berço mais nobre ou mais riquezas possuam mais do bem comum. Em uma aristocracia, aonde alguns governam por sua virtude, se mede a dignidade segundo a virtude; de tal forma que terá mais o que mais abunda em virtude. ${ }^{28}$

A justiça corretiva, por sua vez, opera nas relaçöes (voluntárias e involuntárias ${ }^{29}$ ) de indivíduos com indivíduos, tanto

\footnotetext{
28 AQUNO, Tomás de. Comentario a la Ética a Nicómaco de Aristóteles, V, 664.

${ }^{29}$ Tomás de Aquino diz que: "Deve considerar-se que o voluntário e o involuntário nas comutaçóes diversificam os tipos de justiça". Comentario a la Écica a Nicómaco
}

Cademos do PPG em Direito UFRGS, Porto Alegre, v. 6, n. 7 e 8, p. 393-420, 2007. 
nas trocas de bens como nas ações de um em relação ao outro. Nesta, a justiça também é uma igualdade, porém, uma igualdade definida como aritmética - que se alcança com uma igualdade de quantidade. ${ }^{30}$ As pessoas, em tais relações, sempre são tomadas como iguais, operando a igualdade apenas entre as coisas (ou açōes). ${ }^{31}$ Por exemplo, $X$ vende um cavalo à $Y$, se o cavalo entregue de $X$ à $Y$ vale dez minas, $Y$ deve entregar o equivalente a dez minas à $X$. Operando uma igualdade entre o que saiu do patrimônio de $X$ e entrou no de $Y$ com aquilo que saiu do patrimônio de X e entrou no de $\mathrm{Y}$, ou seja, $10=10$. Assim, haverá injustiça sempre que o ganho e perda das pessoas envolvidas nas relaçōes não forem iguais. Por exemplo, $X$ deu um soco em $Y^{3.2}$ Aquilo que $Y$ sofreu não é igual aquilo que $X$ sofreu. Assim, o juiz estabelecerá uma pena à X que equivalerá ao sofrimento de $\mathrm{Y}$. Que as trocas de coisas e as açöes entre os indivíduos das comunidades devem ser equivalentes é bastante pacífico, no entanto, gera disputas na comunidade a forma de atribui-lhes valor (a reciprocidade das coisas), pois ninguém troca coisas e ações idênticas em natureza, mas algo distinto que deve ser igua lado - pelo dinheiro ${ }^{33}$ nas coisas e pelo juiz nas ações. ${ }^{34}$

de Aristóteles, $V, 661$. No direito de hoje, primordialmente, as comutaçes voluntárias estẫo no âmbito do direito privado, enquanto as comutaçós involuntárias, por fraude ou violência, estão no âmbito do direito penal.

30 AQUINO, Tomás de Comentario a la Ética a Nicomaco de Aristóteles, V, 674.

3? $\mathrm{EN}, \mathrm{V}, 1131 \mathrm{~b}, 25-1132 \mathrm{a} ; 20$.

32 Aristóteles diz que: "Mesmo que às vezes năo seja a palavra apropriada [ganho], se pode nestes casos falar, em geral de ganho (por exemplo, referindo-se ao que deu $o$ golpe) e de perda (referindo-se à vitima). EN, V, 1132 a, 10.

39. "[...] é preciso que se igualem [os objetos de troca] e, por isso, todas as coisas que se trocam devem ser, de alguma maneira, comparáveis. Para isto se inventou a moeda, que é de algum modo algo intermédio, porque tudo mede, de sorte que mede também o exceso e a falia: quantos pares de sandálias equivalem a uma casa ou a um determinado alimento". EN, V, 1133 a, 19-22. "[..] é preciso que todas as coisas sujeitas às comutaçōes sejam de alguma maneira comparáveis entre si, a firn de saber qual vale mais e qual vale menos. Para isto se inventou a moeda, o dinheiro, pelo qual é medido o preço de tais coisas. Assim, o dinheiro é certo meio, enquanto mede todas as coisas, tanto seu excesso quanto sua deficiencia, enquanto uma coisa ultrapassa a outra". Comentario a la Ética a Nicómaco de Aristóteles, V; 694: O presente trabalho não pretende aprofundar este ponto. Sobre o tema ver: Gauthier et Jolif. Léthique a Nicomaque - Introduction, tradution et commentaire; P. $380-384$.

34. "É por isso que aqueles que discutem recorrem ao juz e acudir ao juiz é acudir à justiça, porque o juiz quer ser como uma personificaçäo da justiça; se busca ao jüz 
Aristóteles, após determinar inicialmente a forma $a^{35}$ da justiça (conforme a expressão da justiça legal nas virtudes morais ou conforme à justiça particular), prossegue com a análise do âmbito da justiça, o qual se divide em justiça política (politikon dikaion) e justiça doméstica (oikonomikon dikaion). A justiça política existe em uma comunidade de vida entre pessoas livres e iguais, sendo, portanto, excluidas deste âmbito todas as relações que não se estabeleçam entre pessoas com tais características: a) de estatuto liure, $e$ b) relacionalmente iguais. Assim, dois graus de exclusão se apresentam quanto à justiça política: as relações de justiça doméstica; e as relações de justiça para com o estrangeiro. As primeiras dão-se entre pessoas desiguais em estatuto ou em relação, como as de senhor e escravo (justo despótico - despotikon dikaion), marido e mulher (justo doméstico propriamente dito oikonomikon dikaion) e pai e filho (justo patriarcal - patrikon dikaion) - estão apartadas do âmbito da justiça política, ou, no máximo, presentes neste campo apenas por analogia ${ }^{36}-$ Aristóteles o reafirma sob o argumento de que a justiça política pressupôe relações reguladas por uma lei em comum, que dá um discernimento entre o justo e o injusto. ${ }^{37} \mathrm{E}$ as

como meio termo e alguns chamam aos juzzes de mediadores, acreditando que se alcançam a intermediação sé alcançará a justiça. Portanto, a justiça é um meio termo, posto que o juiz o én", EN, V, $1132 \mathrm{a}, 20-25$.

"Quando os homens têm dúvidas sobre este meio [o justo meio] recorrem ao juiz, que é a mesma coisa que se recorressem ao que é justo, pois o juiz deve ser como o justo: animado". Tomàs de Aquino, Comentario a la Etica a Nicómaco de Aristóteles, V, 678 . "É por isso que aqueles que discutem recorrem ao juiz, e acudir ao jujz é acudir à justiça, porque o juiz quer ser como uma personificação da justiça; se busca ao juiz como meio termo e alguns chamam aos jufres de mediadores, acreditando quie se alcançam a intermediação se alcançarấ a justiça. Portanto, a justiça ế um meio temo, posto que o juiz o én. EN, V, 1132 a, 20 - 25.

"Quando os homens têm dúvidas sobre este meío [o justo meio] recorrem ao juiz, que é a mesma coisa que se reconressem ao que é justo, pois o juiz deve ser como o jusio animado". Tomás de Aquino, Comentario a la Eưica a Nicómaco de Aristóteles, V, 678. 35 A denominação desta classificação como forma e âmbito da justiça deve-se a Mateus Baldin, em conversas sobre o tema.

sor analogia, se entende igualdade de relaçöes entre temos diferentes. Tópicos, 1 , 18 , $108 \mathrm{a}, 8 \mathrm{ess}$

3 EN, V, 1134 a, $25-35$ 
segundas simplesmente não se manifestam em nenhum grau, ou seja, sequer por analogia.

A justiça política subdivide-se em Natural (phisikon) e a por convenção ${ }^{38}$ (nomikon): Natural é aquela que tem em todas as partes a mesma força e não está sujeita ao parecer humano; $e$, por convençấo, aquela que, em sua origem, tem como objeto uma ação indiferente, mas que deixa de o ser depois de determinada. ${ }^{39}$ Aristóteles ressalva, entretanto, que ambas, no mundo sublunar: ${ }^{40}$ são mutáveis; mesmo a justiça natural. Assim como o destro por natureza que pode treinar para tornar-se ambidestro, a justiça natural está sujeita a mutações, porém isso não tem a força de transformar toda a justiça política em convencional, como queriam alguns sofistas. E mesmo a justiça por convenção tem como limites da determinação a realidade particular de cada comunidade, alheia ao parecer humano. Aristóteles dá o exemplo das medidas que devem ser proporcionais àquilo que é medido. ${ }^{41}$

\section{A Amizade A2 $^{4}$}

A Filosofia Política Moderna abandonou um tema de essencial importância dentro da teoria Aristotélica, a saber; a

\footnotetext{
3 Tambên traduzida por Legal. Porếm, aqui se opta pelo termo justiça por convençã̃o como subdivisão da justiça política (em oposiçăo à justiça natural) para não confundir com justiça legal como forma da justiça (em oposiçâo à justiça particular).

${ }^{39}$ Que contespondem a les particular e a le comum (ou natural). Entendamos por fazer injustica o inferir woluntariamente um dano contra a lei $\mathrm{A}$ lei se divide en patticular e comum Chamo farticular a lei escrita, segundo a qual se regem os povos; e comum. a que, sem estar escrita, parece ser admitida por todos". Ret., I, $1368 \mathrm{~b}$.

${ }^{3}[. .$.$] divido a lei em particular e em comum: particular a estabelecida para cada$ povo com respeito a ele mesmo, e esta é em parte näo escrita e em parte escrita. Comum é a lei conforme natureza. Pois de acordo com esta existe algo comumente justo e injusto, o qual todos advinham, ainda que não exista nenhum acordo comum entre uns e outros povos, nem pacto algum; [.. ] Ret. $1,1373 \mathrm{~b}$.

40 Aquele em que o homem vive, das coisas corruptiveis.

4. $\mathrm{EN}, \mathrm{V}, 1134 \mathrm{~b}, 20-1135 \mathrm{a}$

42. Segundo Enrico Berti, "Pela palavra "amizade" (philia) Aristốteles entende todas as formas de atração que um ser humano expenimente em relaçăo a outro ser da mesma especie, ou seja, o amor dos pais em relaçäo aos filhos (e a reciproca), do
} 
amizade. ${ }^{43}$ Para Aristóteles, "A tarefa da política consiste, sobretudo, ao que parece, em promover a amizade". ${ }^{4}$ Uma vez que, "Se se deseja fazer com que os homens não se tratem injustamente, basta torná-los amigos, pois os verdadeiros amigos não cometem injustiças um contra o outro" ${ }^{45} \mathrm{E}$ mais, as instituições que formam a cidade $e$, consequentemente, permitem a política, e a busca à vida boa são obras da amizade.

É claro portanto, que uma cidade não é uma comunidade de residência cujo fim seja apenas evitar a injustiça mútua e facilitar as trocas comerciais. Todas estas condições devem estar presentes para que a cidade exista; mas a sua presença não é suficiente para constituir. O que constitui uma cidade é uma comunidade de lares e de familias com a finalidade da vida boa e a garantia de uma existência perfeita e autônoma. Isto não se realizaria sem que os membros da cidade residam num mesmo lugar e se casem entre si. Daqui surgiram nas cidades as relaçóes de parentesco, as fratrias, sacrificios públicos, e os lazeres. Estas instituições são obras da amizade - jấ que a amizade é condição de escolha de uma vida em comum.

A finalidade e o objetivo da cidade é a vida boa, e tais instituiçōes, propiciarn este fim. A cidade é constituída pela comunidade de familias em aldeias, numa existência perfeita e auto-suficiente; e esta é, em nosso juízo, a vida boa e feliz. ${ }^{46}$

A amizade é, assim, o impulso altruístico de reciprocidade que ocorre nos indivíduos e que se torna, dentro da comunidade como um todo, o laço de coesáo que garante a unidade política, cívica e social ${ }^{47}$ Portanto, pode-se dizer

marido em relaçáo esposa (e vice-versa), do amante para com o amado e do que chamamos amigo em sentido proprio para com o amigo". Berti, A relaçăo enire as formas de amizade segundo Aristóteles In: Analytica, vol 6, n 1. P 23.

43 VILLEY, Michel. Filosofia do Direito. Sä Paulo: Martins Fontes, 2003 . P. $81-82$.

${ }^{44} \mathrm{EE}, \mathrm{VII}, 1234$ b 24 .

$45 \mathrm{EE}, \mathrm{VI}, 1234$ b 33 .

4 Politica, III, 1280 b 30 - 1281 a 4. [Não hấ grifos no original]. Ver também: Folítica, IV. 1295 b $21-25$.

47 AMARAL, Antonió Campelo e GOMES, Carlos de Carvalho. In Aristóteles, Polítca. Ed. Vega. P. 610 , nota 44 
que a chave para compreender a amizade em Aristóteles ${ }^{48}$ está na idéia da relação entre indivíduos e do bem que se segue dessa relação. A amizade é, acima de tudo, ver a si mesmo no outro, como diz Aristóteles, "amigo é um outro eu".45 De forma que o amigo trata ao outro como trata a si mesmo e o bem dele é o seu próprio bem. "Perceber e conhecer a um amigo deve ser, em certo modo, perceber-se e conhecer-se a si mesmo". ${ }^{\circ} \mathrm{E}$ a condição humana é tal que conhecer a si obrigatoriamente passa por conhecer o outro. ${ }^{51}$ Assim, há amizade em relação a todo homem, naquilo que ele tem de igual. $^{52}$

A amizade é uma disposição natural de todo homem..$^{53}$ Porém, uma disposição que um homem não consegue atingir sozinho, em razão de ser uma disposição recíproca, ${ }^{54}$ ou seja, que exige uma ação do outro. ${ }^{55}$ Assim, a amizade apresenta

\footnotetext{
Segundo Werner Jaeger a análise aristotêlica da amizade em seus primeiros trabalhos segue um ideal platônico. Nas suas obras da maturidade (particularmente, neste caso, a EN), a análise seguiria uma análise psicológica e sociológica. JAEGER, Werner Aristotle. Oxford University Press. 2 ed.1962. P.244245.

As origens da teoria da amizade aristotélica sáo evidentemente platónicas, como se pode observar nas semelhanças das abordagens entre o diálogo Lisis de Platão e as éticas aristotelicas Como se verá, em seguida, há realmente uma abordagem diferente na EE e na EN. Poderia discutir-se se isto significa um afastamento da teoria platônica e se de fato seria um indicio de que a EN é posterior a EE (como pretende Jaeger). No presente trabalho, não discutiremos isto. No entanto, e interessante para o presente trabalho a ideia de que Aristóteles realizou uma abordager psicologica e sociologica, pois isto reforca a tese de que o estudo da amizade (como ela se forma e como se manifesta) é uma condiça para a política.

4 EN, IX, 1166 a 30 e 1169 b 5 e 1170 b 5 .

$50 \mathrm{EE}, \mathrm{VI}, 1245$ a $30-35$.

5. AUBENQUE, Pierre. Sur Lamitie chez Aristote. In: La Prudence Chez Aristote. Paris Presses Universitaires de France 1983. P 182.

52 Neste sentido, as seguintes passagens: "Nas viagens também pode se observar quanto farniliar e amigo e todo o homem para todo homem". EN, VII 1155 a 20 . E "Não há amizade com relação a um escravo enquanto escravo, mas sím há enquanto homem, porque parece existir uma certa justica entre todo o homem e todo o que pode participar de uma comunidade na qual há lei ou convencao, e portanto, tambem. amizade na medida en que cada um deles e um homem. EN IX 1161 b $5-15$.

53 A amizade peffeita se dá exclusiva no homem, enquanto os demais tipos de amizade năo săo exclusivamente humanos, Anstóteles expôe como uma caracteística natural da maioria dos animais EE, VII, 1236 b 7.

54 Consequentemente se dirige apenas as colsas animadas, cuja condiça de reciprocidade pode ser cumprida.
}

55 EN, VIII, 1155 b 29 e EE, VII, 1236 a 15 
cinco características: (a) uma disposição interna; ${ }^{56}$ (b) em relação ao outro; (c) recíproca; ${ }^{57}$ (d) não oculta; (e) na qual cada um deseja o bem do outro ${ }^{58}$ (benevolência ou boa vontade eunoia), cuja natureza é uma virtude (arete) ou algo que acompanha a uma virtude. ${ }^{59}$ Assim como a justiça e outras virtudes, ${ }^{60}$ a amizade pode se apresentar como um hábito ou uma ação - ou seja, pode se apresentar como uma inclinação do sujeito, como também na convivência - que é a expressão de sua ação. E é, sobretudo, uma condição necessária à vida, leia-se, à vida boa (eudaimonia) ${ }^{62}$.

56 "[.] sua função [a da amizade] e una atividade, que nao é exterior senáo intenor naquele que ama, enquanto que a funçâo de toda faculdade exterior, pois se encontra ou em outro ou no mesmo ser enquanto outro." EE, VII, $1237 \mathrm{~b}$.

${ }^{57}$ Resultante de uma escolha mútua. EE, VII 1236 b 5.

58 "[...] 0 amigo é aquele que leva a cabo, por causa do outro, $q$ que julga que é bom para ele?. Ret, Livro $1,1361 \mathrm{~b}$.

59 "Isto [a reciprocidade] parece somar-se ao modo da virtude, pois, em qualquer virtude, basta 0 ato do virtuoso, mas, na amizade, não basta o ato de um so senão que é necessário que concorram os atos de dois que mutuamente se querem. Por isso, Aristốteles nào disse acabadamente que era uma virtude senấo que acrescentou ou com unude, porque parece que algo acrescenta a amizade à noçäo de virtude". AQUINO, Tomás de Comentánios a la Ética a Nicómaco de Aristóteles, VIII Lição V 1137.

Outro indicativo para determinar que o entendimento de Aristóteles é de que a ami zade e algo que acompanha uma virude e nao uma virtude e que, oomo visto stipra a justiç, para Aristóteles, e a unica das vitudes que se diz em relaçâ ao outro. Forém, a amizade também se dă em relação ao outro, $O$ que pode-se entender de três formas: a) ou, a amizade năo se dá em relaçâo ao outro; b) ou, quando Aristóteles falou que a justiça é a única virtude em relaçấo ao outro, ele năo contemplava ainda a amizade; c) ou a amizade não e uma virtude, mas algo que acompanha uma virtude Parece que a terceira alternativa $e$ a mais coerente com o pensamento aristotelico.

Ainda, há diversas passagens nas quais Aristóteles dissocia a amizade das virtudes; por exemplo, (EN, X, 179 b 33-35): "Por conseguinte, se ja discutimos o suficiente em termos gerais sobre estas matérias, e sobre as virtudes, e também sobre a amizade e o prazer $[\ldots]^{*}$ :

* Em que pese năo ser exatamente uma virtude, a amizade se expressa da mesma maneira que as virtudes.

6 EN, VIII 1157 b 5. "[..] nas virudes há quem seja chamado bom e virtuoso segundo o hábito, como os valorosos ou os liberais, mesmo quando nâo exercam atos de vintude: Outros sao chamados virtuosos segundo exercam em atos obras de vitude. $O$ mesmo boorre na amizade, uns se dizern amigos em ato, na medida em que convivem com deleite mútuo e se fazem o bem um ao outro, o qual parece pertencer ao ato de amizade Outros, por outro lado, nâ realizam em atos obras de amizade, mas têm disposiço habitual que os inclina a realizar tais obras, cono se ve nos amgos enquanto domem ou quando se distanciam do lugar pois a amizade como tal näo se dissolve pela distancia senầo somente o ato da amizade. Assim é claro que a amizade se. mantém segundo o hábito, ainda que no caso de cessar $o$ ato de amizade". AQUINO, Tomás de Comentánios a la Ética a Nicómacó de Aristóteles, VII, Liçäo V, 1128. 62 "[...] 0 mais necessítio para a vida". EN, VIII, 1155 a 1 .

Cadernos do PFG em Direito UFRGs, Forto Alegre, vi $6, n .7$ e 8 , p. 393 420, 2007 
O objeto da amizade é o amor. ${ }^{63} \mathrm{E}$ as causas pelas quais os homens amam são três. Conseqüentemente, três também são os tipos de amizades: por interesse, por prazer ou pela virtude. Os que se amam por interesse se amam na medida em que um pode beneficiar o outro em razão de outra coisa; os que se amam por prazer se amam na medida em que um pode agradar o outro em seus sentidos - amam pelas paixões e não por uma escolha ${ }^{\text {ta }}$ Portanto, nestes dois casos, o sujeito amado năo é amado por si mesmo, mas como um meio para gerar o que é útil ou agradável ao outro. De tal forma que são amizades apenas por acidente ou por analogia $a^{65}$ e duram apenas enquanto durar estes efeitos. ${ }^{66}$ Por outrolado, a amizade perfeita (teléia philia) é aquela que, formada em razăo da virtude dos amigos, ocorre entre os homens bons e iguais em virtude, porquanto querem o bem um do outro, em razão apenas do outro em si, ${ }^{67} \operatorname{logo}$, é uma amizade tâo estável quanto a virtude ${ }^{68} \mathrm{E}$, neste tipo de amizade, a utilidade e o prazer não são a sua

${ }^{63}$ Conforme Gauthier e Jolif, o amável é o objeto fornal da amizade. L'Ethique a. Nicomaque, Éditions Béatrice-Nauwelaerts, Paris: 1959, P. 670 .

* AQUINo, Tomás de Comentários a la Ëtica a Nicómaco de Aristóteles VIil Lição III, 1108.

${ }_{65} \mathrm{Na}$. EN se expressa como um acidente, enquanto na $\mathrm{EE}$, mais como uma analogia. For acidente se entende "aquilo que pertence como atributo a un sujeito sem ser nem sua definição, nem seu gênero, nem uma propriedade ${ }^{*}$. Tópicos, $1,8,103$ b 18. Ou mais detalhadamente, "um acidente ế (1) alguma coisa que, não sendo nada do que precede - isto é, nem uma definição, nem uma propriedade, nem um gênero - pertence, no entanto à coisa; (2) algo que pode pertencer ou näo pertencer a alguma coisa, sem que por isso a coisa deixe de ser ela mesma, como por exemplo, a posiçäo sentada' pode pertencer ou deixar de pertencer a alguma coísa idêntica a 51 mesma. E do mesmo modo a 'brancura', pois nada impede que uma mesma coisa seja branca em dado momento e em outro momento não o seja". Tópícos, I, 5, $102 \mathrm{~b} 3$ ess.

For analogia, como visto supra, se entende igualdade de rêlaçóes entre temos diferentes. Tópicos, $I, 18,108$ a 8 e ss.

Não se diferencia, no presente trabalho, os diferentes tipos de analogia. Para um estudo do tema, ver as indicaçôes de Enrico Berti: Pierre Aubenque, Les origines de la doctrine de lanalogie de l'être. In: Les études philosophiques, 103, 1978. E, Enrico Berti, Lanalogia in Aristotele. Interpretazioni recenti e possibili sviluppi. In: Origini e sviluppi dellanalogia da parmenide a S. Tommaso, Vallombrosa, 1987.

${ }^{66} \mathrm{EN}$, VIII, 1156 b 1-20.

67 "[...] aquele que se escolhe por si mesmo". EE, VII, 1236 b 30 . Ver também: EE, VII, 1240 a 25 .

68 Para o letor modemo soa estranha a idéia de permanência da virude. Segundo Gauthier e Jolif quando Aristóteles diz que a virtude é duravel ele porta um otimismo 
causa, são seus efeitos. É por si e não por acidente. ${ }^{69} \mathrm{E}$, podese dizer, que este tipo de amizade é um paradigma que serve como padrão ao comportamento do amigo. ${ }^{70}$ No entanto, é natural que amizades perfeitas sejam raras porque poucos homens existem assim. ${ }^{71}$

Pode-se dizer, então, que entre a amizade perfeita e os outros tipos de amizade, existe uma relaçẫo como a do todo com suas partes, uma vez que a amizade perfeita abarca todos os bens (utilidade, prazer e virtude) ${ }^{72}$ É uma relação gradual $^{73}$ na qual a amizade por prazer apresenta uma amplitude maior de amizade do que a amizade, por utilidade, que se apresenta como o menor grau possivel de amizade. ${ }^{74}$ Assim, a amizade por virtude é completa e duradoura, ocorre entre os homens bons e é simetricamente recíproca, é o caso central de amizade por apresentar todos os bens que se manifestam apenas por acidente nos demais tipos. Enquanto a amizade por prazer, formada normalmente entre os jovens, ${ }^{75}$

incompativel com a visão cristâ, uma vez que o pecado ameaça sempre a fragilidade da virtude. LEhique a Nicomaque, Editions Beatrice-Nauwelaerts, Paris: 1959, P. 677. O que, de certa forma, explica a compreensão moderna de que as virtudes nâo auxiliam a política. Uma vez que estas são efêmeras, näo influenciam a política que ê permanentemente.

69. Comentários a la Ética a Nicốmaco de Aristóteles, VII, Liçăo III, 1111.

$7^{\circ}$ Conforme interpretaçäo de GANNOTI1, José Arthuri. O Amigo e o Benfeitor. İn: Analytica, vol. 1, n. 3.

${ }^{71} \mathrm{EN}$, VIII, 1156 b $5-25$

${ }^{72}$ Os comentadores demonstram que a relação entre os tipos de amizade é apresentada diferentemente na EN e na $\mathrm{EE}$, como uma relação de semelhança ou de unidade focal. O presente trabalho năo aprofunda a questão em razâo do seu objeto, mas adota a abordagem da EN. Para um estudo da qquestão, ver: BERT, Enrico. A relaçào entre as formas de amizade segundo Aristóteles. In: Analytica, vol $6, n$ 1. René Lefebvre, Referencia e semelhança: As amizades de Ariștóteles. In: Analytica, vol $6, n 1$. Gauthier et Jolif. Léthique a Nicomaque - Introduction, tradutionet commentaire, Tome II:

73. "Os imãos e os companheiros têm tùdo em comum; mas os outros têm apenas certas coisas, uns mais e outros menos, pois tamberm as amizades säo umas mais e outras menos. Na justiça também há diferenças, pois o que é justo para os pais em relação aos filhos, não é o mesmo que ê justo entre os imaăos, nem entre os companheiros e os cidadãos [...]" EN, VIII, 1159 b 30.

${ }^{7} \mathrm{EN}, \mathrm{VIII}, 1157$ a $5-25$.

75 Aristôteles diz que se dá entre os jovens, porque estes săo mais propensos à concupiscência: 
não é muito duradoura e pode se dar de forma perfeitamente recíproca ou assimétrica. $E$, por fim, a amizade por utilidade que se apresenta como o menor grau de amizade e que dura pouco tempo, normalmente vista entre os velhos ${ }^{76}$ e os homens maus e que normalmente se dá de forma assimétrica, haja vista que os interesses dos amigos normalmente divergem?

Na amizade por utilidade, pode-se determinar seu âmbito de duas formas: em amizade doméstica, ${ }^{78}$ que se dá naturalmente entre os parentes ou entre aqueles que se criaram juntos, 7 e amizade política, entre membros de uma comu nidade, ${ }^{30}$ esta, por sua vez, pode novamente ser subdividida em duas: legal e ética: a amizade legal ${ }^{81}$ se forma baseada em um acordo, assim, considera a coisa recebida na estrita medida do intercâmbio de utilidade - deve-se considerar como os amigos podem tirar proveito de seu acordo - é o tipo de amizade mais necessária na vida em comunidade; ao passo que a amizade ética ${ }^{82}$ se forma baseada na confiança, assim,

\footnotetext{
7 Aristóteles diz que se dá entre os velhos porque estes necessitam de cuidados.

77 . As amizades ainda podem ser heterogêneas, ou seja, nas quais se troca prazer por utilidade' Săo amizades nas quais não há permanência, pois, "Aqueles que, na amizade, não retribuem o prazeroso pelo prazeroso senäo o util pelo prazeroso; säo menós amigos por ter uma menor semelhança $\epsilon$, por isso, permanecem menos na sua amizade". AQUINO, Tomás de. Comentários a la Ética a Nicómaco de Aristóteles, VII, Lição $I V, 1123$.

Para Gauthier e Jolif a ideia de amizade heterogênea parece, em um primeiro momento um quarto tipo de amizade em Aristóteles mas adiante ele esclarece que se trata de um novo princípio de divisáo das amizades homogêneas e heterogêneas. Aplicada esta classificação às três formas apresentadas antes, restam seis tipos de amizade em Aristóteles. Ainda, pode acrescentar-se 0 criténo de amizades entre iguais e entre desiguais, totalizando doze tipos de amizade. Ver Gauthier e Jolif LEthique a Nicomaque, Editions Béatrice-Nauwelaents Pars: 1959, P. 688 .

78 Aristóteles chama de parental.

${ }^{79}$ Subdivide-se em yárias espócies: uma, entre parentes, isto é, entre fimàos, ou entre pai e filhos, Outra entre o que hoje se entende por amigo de infancia propriamente dito (hêtairoil). Ver: Gauthier e Jolif L'Ethique a Nicomaque, Éditions BéatriceNauwelaerts, Paris: 1959, P. 687.

EE, VII 1242 a 15 .

st Também chamada de política cu cívica.

8. Também chamada de fraterna ou de companheiros.

Que exista a amizade ética é essencial para determinar -- como fará Aristóteles -.., que a polis exista por natureza, uma vez que a amizade politica é condição necessária
} 
se considera a intençẫo do amigo, de tal forma que, um amigo age corretamente com o outro se, depois de ter recebido grandes beneficios, os corresponde na medida se suas possibilidades - é o tipo de amizade mais nobre. ${ }^{83}$

Após, Aristóteles determina os efeitos da amizade: a benevolência, a beneficencia e a concórdia. A benevolência é o início da amizade, é uma boa disposição interior em relação a uma pessoa, inclusive em relação a um desconhecido. A beneficência é a voluntária prestação de beneficios aos amigos. ${ }^{85}$ Por fim, a amizade também mantém unidas as cidades, através da concórdia, ${ }^{86}$ cuja expressáo pode ser formulada de diferentes maneiras. A concórdia é a amizade civil que ocorre nas cidades, pois está relacionada com o que convém e com o que afeta a vida em comum de seus cidadãos $^{87} \mathrm{E}$ a igualdade de pensamento (homonóia) entre os cidadãos sobre o que lhes convém, é a igualdade de escolha e realização no que é de comum interesse. É o mesmo parecer, por parte dos cidadãos, nas matérias práticas e relevantes, como, por exemplo, na forma de escolha das magistraturas. Assim, pode-se dizer que o sujeito de tal concórdia é o homem bom, posto que os homens bons querem o que é justo e conveniente e a isto aspiram no comum em harmonia. Consequentemente, os maus são os sujeitos da discórdia, pois não podem concordar exceto em pequena medida, haja vista que, nos benefícios, desejam receber mais do que thes corresponde, e nos ônus, querem menos do que aquilo que thes corresponde, dando início à injustiça ${ }^{80}$

\footnotetext{
a pólis, porem a confiança (própria da amizade éica) se dá naturalmente, enquanto um acordo (proprio da amizade legal) näo. Desenvolver se á no ponto sobre o direito. 8 EN, VII, 1162 b $15-35$ e EF, VI, 1242 b $35-1243$ b 11 ,

EN, IX, 1167a.

85 AQUINO, Tomás de Comentários a la Etica a Nicomaco de Aristóteles, IX, Lição IV, 1293.

B6 EN, VII, 1155 a 22 .

s7. "Pof sua vez, a amizade política está constituida principalmente en funçäo da ufilidade que parece que os homens, por nầ se bastar a si mesmos, se reuniram, mesmo que tenham se reunido tambem para viver juntos. [...] A amizade baseada na igualdade 6 a amizade civica. Esta por um lado se baseia na utilidade, e as cidades são amigas entre si da mesma maneira que os cidadäos". $\mathrm{EE}^{2}, 1242$ a 5-10 e 1242 b $20-30$.

EN, IX, 1167 a 20-1167 b 15 e EE, VI, 1241 a 1-35.
} 


\section{A Amizade como o Fim do Direito}

Para determinar a causa final do direito ${ }^{89}$ na amizade, se faz necessário discorrer sobre as relaçóes entre a amizade e a justiça. A análise dessa relação dá indícios de que a amizade se apresenta em uma relação muito próxima com a justiça. Passa-se a analisar se essa relação é o movimento entre a coisa e seu fim. Dois são os pontos da teoria de Aristóteles que fundamentam tal hipótese:

(a) como visto supra, existem dois tipos de amizade política - legal e ética -, a amizade legal é a mais necessária à vida em comunidade (apesar da ética ser a mais nobre). Assumindo que existe um tipo de amizade legal, evidenciase que existe uma forma de amizade causada pela justiça. Apesar de que nem toda amizade possa ser causada pelo direito. ${ }^{\infty}$ No entanto, como visto anteriormente, existe uma forma de amizade política que é expressão da amizade legal, a qual pode ser causada pelo direito, qual seja, a concórdia,"? a qual não depende de muitos fatores e pode realizar-se até em homens que têm uma certa distância, ${ }^{92}$ sendo assim uma amizade formal. ${ }^{93}$ Segundo John Morrall,

\footnotetext{
Nesta análise, odireito confunde-se com a sua causa formal, portanto, são intercambiâveis, aqui, as expressóes justiça e direito. Ver: ALVARFZ, Alejandro. As relaçōes entre ética, política e diresto em aristóteles.

90 Porém, indiretamente, a amizade pela virtude pode seguir-se, indiretamente do direito uma vez que esse, através das leis, é o responsável por incutir as virtudes nos cidadâos, como visto supra.

"De acordo com o estudado anteriormente, no capitulo 2.2 , a concórdia é a amizade civil que ocorre nas cidades, pois está relacionada com o que convém e como que afeta a vida em comum de seus cidadãos. Éa igualdade de pensarnento (homonóia) entre os cidadãos sobre o que thes convêm, é a igualdade de escolha e realização no que é de comum interesse. $\dot{E}$ o mesmo parecer, por parte dos cidadãos, nas matérias práticas e relevantes, como na forma de escolha das magistraturas.

92 Neste sentido, as seguintes passagens: "Nas viagens, tambem pode se observar quanto familiar e amigo é todo o homem para todo homem". EN, VIII, 1155 a 20. E "Não há amizade com relação a um escravo encuanto escravo, mas sim há enquanto tomem, porque parece existir uma certa justiça entre todo o homem e todo o que pode participar de uma comunidade na qual há lei ou convençăo, e, portanto, tambem, amizade na medida em que cada um deles é um homem". EN, IX, 1161 b $5-15$.

${ }^{3}$ O que é muito compativel a idéia apresentada por Wadimir Lisboa, em seu artigo que fundamenta o direito, conforme Aristoteles, de que " $[\ldots]$ o direito tem por
} 
[a] formação da associação política é relacionada por Aristóteles, a tendência humana de buscar amizade. [...] a amizade pode resultar em homonoia (semelhança de idéias, unanimidade ou concordância). Isso tem ligação com a política; 'a concordância é a amizade entre os cidadãos de um estado, e seu campo sấo os interesses e preocupações da vida' [EN, IX, 1167 b]. Aqui, aparece também a concepçáo de um interesse comum, possivelmente obtenível mediante a harmonização dos interesses individuais [... ${ }^{94}$

Essa interpretação de Morrall confirma a possibilidade ${ }^{9.5}$ de que a causa final da justiça seja a amizade, pois essa harmonização dos interesses individuais, como visto anteriormente, é realizada pelo direito, desde seu início, através da lei, na busca constante da igualdade, a qual, posteriormente, sustenta amizade cívica entre os cidadẫos.

(b) Aristóteles é expresso em dizer que com a amizade se dá o fim da justiça; faz-se necessário, então, investigar se isso pode ser interpretado no sentido de que a justiça tende à amizade.

Crê-se que a justiça é igualdade e que a amizade se encontra na igualdade, se nãoé em vão como se diz: "a amizade é uma igualdade'. Todas comunidades (koinonia), e todo o comum se funda na justiça. Por conseguinte, há tantas espécies de amizade como de justiça e de comunidade; e todas estas espécies lindam umas com as outras e têm diferenças pouco perceptíveis. ${ }^{96}$

objetivo último regular a convivência dos homens na comunidade". A ciếncia do direito e o problema dos fundamentos - prolegomenos à filosolía do direito. Estudios Jứídicos, Vol 26, n. 66, 1993. P. 14.

4 MORRALl a John. Aristóteles. Brasilia: Editora UNB, 2000. P. 45. Năo há grifos no original.

95 So da análise dos dois pontos em conjunto pode-se seguir a necessidade de que a amizade seja a a causa final do diretio.

EE, VII, 1241 b 1015 
A amizade se funda na igualdade ${ }^{97}$ e existe em virtude de uma semelhança. ${ }^{98}$ É neste ponto que reside a principal diferença entre a amizade e a justiça. Enquanto a amizade parte da igualdade, que the é anterior e se manifesta como expressão dessa igualdade, a justiça busca a igualdade, que, portanto, lhe é posterior, como um meio de ajustar as relações conforme a igualdade devida entre os sujeitos da relação. ${ }^{99}$ Assim, a justiça tende para a igualdade na qual se desenvolve a amizade. Daí Aristóteles afirmar que: "Quando os homens são amigos, nenhuma necessidade há de justiça, mas, mesmo sendo justos, sim necessitam da amizade, e parece que são os justos os mais capazes de amizade" ${ }^{100} \mathrm{Ou}$, nas palavras de Tomás de Aquino: "Daí que à amizade pertença usar de alguma maneira a igualdade já constituída, mas à justiça pertence reduzir à igualdade o desigual. Dando-se a igualdade, cessa o ato de justiça. Por isso, a igualdade é o último na justiça, mas o inicial na amizade".

Dessa decorre duas possibilidades: ou a justiça tende à igualdade e a amizade inicia-se da igualdade sem que haja um ponto de contato, ou, realmente, a amizade é a causa final do direito. Para buscar a interpretação correta, deve-se dar um passo atrás e relembrar que o ato próprio da justiça é igualar e que a amizade é a expressão dessa igualdade e,

\footnotetext{
${ }_{97}$ Amizades nas quais não há igualdade entre os amigos săo amizades apenas em seu sentido análogo, em que se devem igualar as açôes que the correspondem para

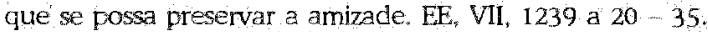

A amizade na comunidade democrática se baseia na igualdade entre os amigos e. conseqüentemente, igualdade numérica entre as açöes, enquanto a amizade na comú nidade aristocrática e na monárquica se baseia na desigualdade entre os amigos $e$, consequentemente, igualdade proporcional nas açōes, de acordo com a superioridade ou inferioridade dos que dela participam. EE; VII, 1241 b $30-35$. Ver tambem: EN, vIII, 1158 b e Tomás de Aquino. Comentários a la Ética a Nícómaco de Aristóteles, VIII, Liçăo VII, 1157.

FN, VIII, 1156 b 20.

A igualdade $e$ anienor na amizade sob duplo aspecto: igualdade entre os sujeitos (que é a causa da amizade) e igualdade nos bens (que é um dos efeitos da amizade). Ver: EN, VII, 1156 b 15; EN, VII, 1158 b; EN, LX, 1169 b 5; EN, LX, 1170 b 5; EE, VI,

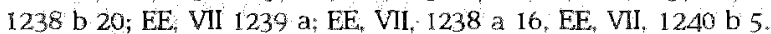

$100 \mathrm{EN}$, VIII 1155 a 25

AQUINO, Tomás de Comentários a la Ética a Nicómaco de Aristóteles, V.
} 
portanto, não existe de fato esse ponto intermediário; năo teria nenhum sentido Aristóteles dizer, por exemplo, que quando há amizade não há nenhuma necessidade de buscar a igualdade.

\section{Conclusão}

Tanto a justiça quanto a amizade, como formas de relação na sociedade, são condiçóes necessárias ao desenvolvimento da Política e do direito, expressando as relações de igualdade ou desigualdade próprias do âmbito político, estas dâo o sustento de toda a pólis.

Aristóteles expõe a justiça sob duplo aspecto: (a) como forma de se relacionar com os demais membros da comunidade (virtude completa), como expressão de qualquer das virtudes de determinado agente usada para a realização do bem de toda comunidade, ou, (b) como hábito (virtude particular), cuja natureza não é distinta das demais virtudes particulares. A justiça é sempre relacional, isto é, sempre tem por finalidade o bem do outro. Porém, enquanto a justiça geral (virtude completa) visa diretamente ao bem da comunidade em geral - o bem comum - e indiretamente ao bem dos indivíduos; a justiça particular (virtude particular) visa diretamente ao bem do particular e indiretamente ao bem comum. O âmbito da justiça se divide em justiça política e justiça doméstica. A justiça política existe em uma comunidade de vida entre pessoas livres e iguais, excluîdas deste âmbito todas as relações que não se estabeleçam entre pessoas com tais características. A justiça política subdivide-se em Natural e por convenção): Natural é aquela que tem em todas as partes a mesma força e não está sujeita ao parecer humano; e, por convenção, aquela que, em sua origem, tem como objeto uma açäo indiferente, mas que deixa de o ser depois de determinada.

A amizade, por sua vez, é o impulso altruístico de reciprocidade que ocorre nos indivíduos e que se torna, dentro da 
comunidade como um todo, o laço de coesão que garante a unidade política, cívica e social. Apresenta cinco características: (a) uma disposição interna; (b) em relação ao outro; (c) recíproca; (d) não oculta; (e) na qual cada um deseja o bem do outro. O objeto da amizade é o amor. $\mathrm{E}$ as causas pelas quais os homens amam são três. Conseqüentemente, três também sẩo os tipos de amizades: por interesse, por prazer ou pela virtude. Os que se amam por interesse se amam na medida em que um pode beneficiar o outro em razão de outra coisa; os que se amam por prazer se amam na medida em que um pode agradar o outro em seus sentidos - amam pelas paixões e não por uma escolha. Portanto, nestes dois casos o sujeito amado nâo é amado por si mesmo, mas como um meio para gerar o que é útil ou agradável ao outro. De tal forma que são amizades apenas por acidente ou por analogia $e$ duram apenas enquanto durar estes efeitos. Por outro lado, a amizade perfeita é aquela que formada em razão da virtude dos amigos, ocorre entre os homens bons e iguais em virtude, porquanto, querem o bem um do outro, em razão apenas do outro em si, logo, é uma amizade tão estável quanto a virtude. $E$, neste tipo de amizade, a utilidade e o prazer não sẩo a sua causa, são seus efeitos. É por si e não por acidente. $\mathrm{E}$, pode-se dizer, que este tipo de amizade é úm paradigma que serve de padrấo ao comportamento do amigo. No entanto, é natural que amizades perfeitas sejam raras porque poucos homens existem assim. Na amizade por utilidade, pode-se determinar seu âmbito de duas formas. em amizade doméstica e amizade política, entre membros de uma comunidade; esta, por sua vez, pode novamente ser subdividida em duas: legal e ética. A amizade legal se forma baseada em um acordo, assim, considera a coisa recebida na estrita medida do intercâmbio de utilidade, é o tupo de amizade mais necessária na vida em comunidade; ao passo que a amizade ética se forma baseada na confiança, assim, se considera a intenção do amigo, de tal forma que, um amigo age corretamente com o outro se, depois de ter recebido grandes benefícios, os 
corresponde na medida de suas possibilidades - é o tipo de amizade mais nobre. Por fim, Aristóteles determina os efeitos da amizade: a benevolência, a beneficência e a concórdia. A benevolência é o início da amizade, é uma boa disposição interior em relação a uma pessoa, inclusive em relação a um desconhecido. A beneficência é a voluntária prestação de beneficios aos amigos. Por fím, a amizade também mantém unidas as cidades, através da concórdia.

A matéria própria do direito (causa material) nos estudos aristotélicos, reside no ato de atribuir o próprio de cada um, ou seja, no ato de dar a cada um o "devido", para que seja (re)estabelecida a igualdade. $\mathrm{O}$ "devido" dá-se de diferentes formas: ao passo que o devido na justiça geral é a conformidade das ações dos indivíduos às disposições da comunidade na forma da lei na justiça particular, o devido é a igualdade. $\mathrm{Na}$ divisão da justiça particular, tem-se a justiça distributiva que opera na distribuição tanto dos bens quanto dos males da comunidade aos seus membros - relação da comunidade com seus membros -, ou seja, na atribuição de coisas que, em um primeiro momento, são comuns a determinados indivíduos - de acordo com uma igualdade proporcional. Temse, outrossim, a justiça corretiva que, por sua vez, opera nas relações (voluntárias e involuntárias) de indivíduos com indivíduos, tanto nas trocas de bens como nas açöes de um em relação ao cutro. Nesta, a justiça também é uma igualdade, porém, uma igualdade definida como aritmética.

E sobre essa teona da justiça que Aristóteles desenvolve sua teoria junidica - a qual terá influência preponderante nos séculos seguintes - sendo, portanto, a identidade do direito em Aristóteles fundada na justiça, sua causa formal.

Existe uma forma de amizade política que é expressão da amizade legal, a qual pode ser causada pelo direito, qual seja, a concórdia. Essa atua como causa final da justiça, pois a harmonização dos interesses individuais é realizada pelo direito, desde seu início, através da lei, a qual, posteriomente, inicia amizade cívica entre os cidadãos. Ademais, Aristóteles 
é expresso em dizer que com a amizade se dá o fim da justiça, isso se deve ao fato de que a justiça tende para a igualdade na qual se desenvolve a amizade. $O$ ato próprio da justiça é igualar e a amizade é a expressắo dessa igualdade, sendo, portanto, a causa final do direito a amizade.

\section{Referências}

AMARAL, Antônio Campelo, GOMES, Carlos de Carvalho. Comentários. In: Aristóteles, Politica. Ed. Vega.

AQUINO, Tomás de. Suma Teológica. São Paulo: Loyola 2005. Volumes IV, VeVI.

L_. Suma contra los Gentiles. México: Editorial Porrua, 1991.

. Comentario a la Política de Aristóteles. Pamplona: Eunsa, 2001.

2000. Comentánios a la Ética a Nicómaco de Aristóteles. Pamplona: Eunsa, Ed. Vozes, 1991.

ARENDT, Hannah. Origens do totalitarismo. São Paulo: Companhia das Letras, 1989.

Entre o passado e o futuro. São Paulo: Perspectiva, 1992

. A Condição Humana. Rio de Janeiro: Forense Universitária, 1995.

ARISTOTELES Obras. Madrid: Aguilar, 1982.

Política Lisboa: Ed. Vega.

Ética Nicomáquea e Etica Eudemia. Madrid: Gredos, 1985.

. Les Topiques. Paris: Librairie Philosophique J. Vrin, 1950.

Organon. Paris: Librairie Philosophique J. Vrin 1946.

Physique. Paris Les Belles Lettres, 1996. $2 \mathrm{v}$.

. Metalísica. Madrid: Gredos, 1982.

Ethique à Eudème Paris Libraire J Vrin, 1997.

. El arte de la retónica. Buenos Aires: Eudeba, 2005.

. De Anima. São Paulo: Editora 34, 2006.

. Constituição dos Atenienses. 
AUBENQUE, Pierre. La prudence chez Aristote. Paris: PUF, 1986. PUF, 1993.

(org.). Aristote politique: etudes sur la politique d'Aristote. Paris:

BARZOTTO, Luis Femando. A democracia na constituç̧ăo. Săo Leopoldo: Editora Unisinos, 2005

Justiça Social - Gênese, estrutura e aplicaçâo de um conceito. Revista do Ministerio Público do Rio Grande do Sul, v. 50, 2003. P. 19-56.

Reconocimiento y fraternidad. ARSP. Archiv für Rechts und Sozialphilosophie, v. III, p. 83 89, 2007 .

Pessoa, Fratemidade e Direito. Anais do I Congresso Sul-Amenicano de Filosofia do Direito, org. Wambert Gomes Di Lorenzo. PUCRS. 2005.

Os Direitos Humanos como Direitos Subjetivos - Da dogmática jurídica à ética. Jưisidição e Direitos Fundamentais. Porto Alegre, v. I, n. I, p. $239-280,2005$.

Prudência e Jurisprudência. Uma reflexão epistemológica sobre a jurisprudência romana a partir de Aristóteles. Direito e Justiça, v.23, ano XXIII, p. 221-250, 2001.

Verbete: ARISTÓTELES, no Dicionário de filosofia Política da Editora Unisinos, ainda no prelo.

BARRNES, Jonathan. Áristóteles. Madrid: Catedra, 1993.

BARREAU, Hervé Aristote. Paris Éditions Seghers, 1972.

BERTI, Enrico. As razões de Aristóteles. São Paulo: Loyola, 2002.

Phrónesis et science politique. In: Aristote Politique, Pierre Aubenque (org.) Pans: PUF, 1993.

A relação entre as formas de amizade segundo Aristóteles. In: Analytica, vol $6, n 1$.

COULANGES, Fustel de A Cidade Antiga. São Paulo: Edipro, 2001.

FERRAZ JUNIOR, Tercio Sampaio. Introduçăo ao Estudo do Direito técnica, decisầo, dominaçāo. São Paulo Allas, 2001. FINNIS, John. Natural Lawa and natural rights. Oxford: Claredon, 1992.

FREUND, Julien. Politique et Impolinique. Paris: Éditions Sirey, 1987.

GAUTHIER, Rene Antone et JOLIF, Jean Yves. Léthique a Nicomaque Introduction, tradution et commentaire, Tomos I e II. Paris; BéatriceNauwelaerts, 1959.

GAUTHIER, Renê Antoine. Introdução à moral de Aristóteles. Lisboa: Publicaçōes Europa-América, 1992.

Cademos do PPG em Direito UFRGS, Porto Alegre, w, 6, n. 7 e 8, p. 393-420, 2007. 
GANOTTI, José Arthur. O Amigo e o Benfeitor In: Analytica, vol. 1, n. 3.

GILSON, Étienne. A filosofia na Idade Média. Săo Paulo: Martins Fontes, 1998.

Le thomisme: introduction a la philosophie de Saint Thomas D'Aquin. 6. ed. rev. Paris: Librairie Philosophique J. Vrin, 1997.

HAARSCHER, Guy Filosofia dos Direitos do Homem. Lisboa: Insituto Piaget, 1993. P. $57-73$.

JAEGER, Wemer Aristotle fundamentals of the history of his development. Oxford: Oxford University Press, 1962.

Paidéia. São Paulo: Martins Fontes, 2001.

KALIMTZIS, Kostas Aristotle on Enmity and Disease. New York: University of New York Press, 2000.

LAMAS, Felix Adolfo. La concórdia política. Buenos Aires: Abeledo-Perrot, (s/a).

LEFEBVRE, René. Referência e semelhança: As amizades de Aristóteles. In: Analytica, vol 6, n 1 .

LISBOA, Wladimir Barreto. A ciência do direito e o problema dos fundamentos - prolegômenos à filosofia do direito. Estudos Jurídicos, Vol, 26, n. ${ }^{\circ} 66,1993$. P.

MACINTYRE, Alasdair. Justiça de quem? Qual racionalidade? São Paulo: Loyola, 1991 . Trás la virtud. Barcelona: Crítica, 1987.

A short history of ethics: a history of moral philosophy from the Homeric Age to the Twentieth Century. London: Rootledge, 1998.

Tres versions rivales de la ética. Madrid: Rialp, 1992.

MANSION, Augustin. Introduction a la Physique aristotélicienne. Louvain: Éditions de Linstitute Supérieur de philosophie, 1945.

MARITAIN, Jacques. O homem e o estado. Río de Janeiro: Agir, 1952. 1967.

. Os Direitos do homem e a lei natural. Rio de Janeiro. José Olympio,

MLLLET, Louis. Aristóteles. São Paulo: Martins Fontes, 1990.

MORRALL, John B. Aristóteles. Brasilia: Ed. Universidade de Brasilia, 2000.

NUSSBAUM, Martha. The fragility of goodness. Cambridge University Press; 1986.

PERRINE, Marcelo. Quatro liçōes sobre a ética de Aristóteles. Sấo Paulo. Ediçốes Loyola, 2006.

PLATÄO. As Leis. Bauru: EDIPRO, 1999.

Cademos do PFG em Direito UFRGS, Porto Alegre, v. $6, n .7$ e $8, p .393-420,2007$. 
. República Lisboa: Calouste, 1990.

REALE, Giovanni. Aristóteles. São Paulo: Ediçōes Loyola, 1994.

SPAEMANN, Robert. Bonheur et bienveillance: essai sur l'éthique. Paris: PUF, 1997.

VILLEY, Michel. Filosofia do Direito. São Paulo: Martins Fontes, 2003.

VEATCH, Henry. O homem racional. Rio de Janeiro: Topbooks, 2006.

VERGNIĚRES, Solange. Ética e Política em Aristóteles. São Paulo: Paulus, 1998.

VOEGELIN, Enic. A nova ciência da política. Brașilia; Editora UNB, 1982.

WOLFF, Francis. Aristóteles e a política. São Paulo: Discurso editorial 1999. 